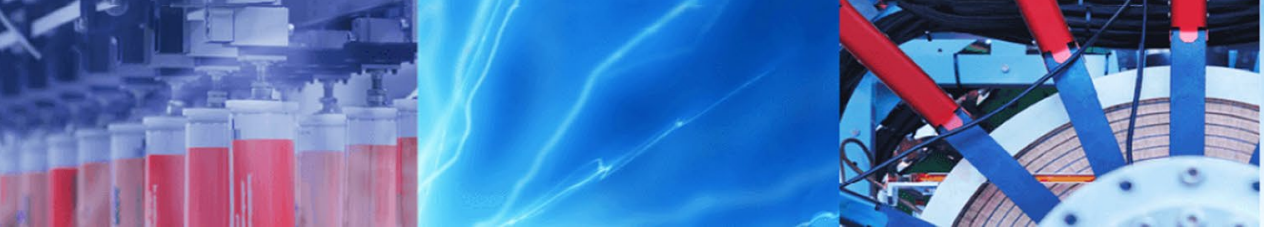

Research Article

\title{
Potential effects of aerosols on the diurnal cycle of precipitation over Central Africa by RegCM4.4
}

\author{
A. J. Komkoua Mbienda ${ }^{1,2} \cdot$ G. M. Guenang ${ }^{1,2} \cdot$ R. S. Tanessong ${ }^{3} \cdot$ A. Tchakoutio Sandjon ${ }^{4}$ \\ (c) Springer Nature Switzerland AG 2019
}

\begin{abstract}
In this study, we examine the potential influence of aerosols on the diurnal cycle of precipitation over Central Africa by analysing 5-year simulations performed with the version 4.4 of the Abdus Salam International Centre of Theoretical Physics model (RegCM4.4). Two sets of 6 years from January 2001 to December 2006 were simulated at a 40-km horizontal grid with 1 year for spin-up. Overall, our results indicate that the simulated seasonal aerosol loads are underestimated everywhere over the study domain compared to MODIS total aerosol optical depth retrieval, except the northern part encompassing Sahel region characterized by an occurrence of dust aerosols loading coming from the Sahelian region in West Africa. The model diurnal precipitation was evaluated against the TRMM 3B42 rainfall product. The diurnal evolution of precipitation reveals that the model represents the general pattern, but always with very low values peculiarly in the late afternoon. Over the rainy area, amplitude of precipitation is systematically affected by either a reduction or an increase by up to $\pm 20 \%$ and $\pm 40 \%$ during DJF and JAS, respectively. Scattering and absorption of solar radiation by aerosols can explain the reduction in diurnal amplitude of precipitation. The time of maximum precipitation is not really affected during both seasons over the major part of rainy area.
\end{abstract}

Keywords RegCM4.4 · Aerosols $\cdot$ Radiative forcing $\cdot$ Diurnal cycle

\section{Introduction}

Africa is one of the regions around the globe which is most affected by climate variabilities. In fact, due to their low capacities for adaptation and mitigation, developing countries are the most vulnerable to the adverse effects of these variabilities. The evidence is now overwhelming that the changes in atmospheric composition are the most important cause of such observed climate variabilities. These changes in climate will lead to important consequences for agriculture, human health and water supply, which result in increased frequency and severity of floods and droughts $[22,42,44,49,50]$. While the climatic effects of greenhouse gas are well known and documented, those of aerosols are still under investigation. Long regarded as marginal, the variability of aerosols on climate has been for several years the object of great attention by the part of scientific community, because one realizes that the amplitude of theses effects is considerable. Indeed, aerosols can interact with radiation and clouds and therefore lead to considerable modulation of precipitation. As mentioned in the Fourth Assessment Report of the Intergovernmental Panel on Climate Change [43], climate models can be used to investigate the changes in some atmospheric parameters such as precipitation and temperature. Because of their fine resolution and therefore their ability to a more realistic representation of fine scale processes [12], regional climate models (RCMs) are commonly used

$\triangle$ A. J. Komkoua Mbienda, kombiend@gmail.com | 'Laboratory of Mechanics and Modeling of Physical Systems, Department of Physics, Faculty of Science, University of Dschang, Po Box 67, Dschang, Cameroon. ${ }^{2}$ Laboratory of Environmental Modeling and Atmospheric Physics, Department of Physics, Faculty of Science, University of Yaounde 1, Yaoundé, Cameroon. ${ }^{3}$ School of Wood, Water and Natural Resources, Faculty of Agronomy and Agricultural Sciences, University of Dschang, Dschang, Cameroon. ${ }^{4}$ Higher Teacher Technical School, University of Buea, Buea, Cameroon.

SN Applied Sciences (2019) 1:141 | https://doi.org/10.1007/s42452-018-0154-0 
for dynamical downscaling by forcing data from global climate models (GCMs) $[1,34,38]$. Moreover, to study the diurnal cycle of precipitation, RCM is preferable than GCM because as pointed out in many studies [7, 8, 29, 31, 45], the GCM-simulated diurnal precipitation usually peaks around local noon instead of late afternoon.

The importance of an accurate quantification of the diurnal precipitation cycle needs to be emphasized not only for the practical purposes, but also for the understanding of the underlying processes and conceptualization of climate models $[16,23]$. In fact, information on the subdaily scale variation of precipitation may be essential for social planning and water resource in particular, and for public activities management in general.

Numerous studies have already been conducted to investigate the effects of aerosols over some regions around Africa continent. Most of them have focused on the seasonal effects of dust aerosols (e.g. [18, 46, 47, 52]) and anthropogenic aerosols (e.g. [27]). They found a significant impact on some atmospheric parameters including, but not limited to, temperature and precipitation, as well as on the hydrological cycle of atmospheric water vapour depending on the area of interest. Because of their short time of residence in the atmosphere and their strong variability in time and space, a particular investigation of the effects of aerosols on the diurnal cycle of precipitation is needed. In addition, transport of aerosols is affected by planetary boundary layer stability which is linked to the diurnal variation of convection and atmospheric stability [6]. So far, very few studies have been carried out in that sense.

Bell et al. [5] in their study regarding air pollution found that aerosol emissions over the large industrial cities over USA have been associated with changes in diurnal cycle of precipitation. Moreover, Kaufman et al. [24] have investigated the effect of pollution aerosol on shallow cloud development. They concluded that the diurnal variation of aerosols affects not only the aerosol radiative forcing, but also the precipitation and cloud by modulating the number of cloud condensation nuclei (CCN). Over West Africa, Lau et al. [30] found that Saharan dust aerosol radiative effects can impact the diurnal cycle of precipitation. This finding has been deeply investigated by Kim et al. [26]. They concluded that aerosols reduce the amplitude of the diurnal cycle of precipitation over land, but the phase of this cycle is not much affected over West Africa.

Till now, none of these kinds of studies aforementioned have been conducted over Central Africa (CA) which is a region characterized by a strong rainfall variability. Therefore, the response of the diurnal cycle of precipitation to aerosols forcing over CA remains unclear. The present study uses a regional modelling approach to assess the impact of the aerosols on the diurnal cycle of precipitation over $\mathrm{CA}$ using simulations involving radiative forcing, which includes the influences of both natural and anthropogenic aerosols. The remainder of this document is organized into the following sections: Sect. 2 describes the methodology, including used data and experimental designs. Section 3 discusses the results. Finally, Sect. 4 summarizes the key points and conclusions from this study.

\section{Methodology}

\subsection{RegCM4 and experimental designs}

In this study, we use the released version 4.4 of the Abdus Salam International Center for Theoretical Physics regional climate model (RegCM4.4) (Giorgi et al. [13, 14] and the references therein). Komkoua Mbienda et al. [28] have already shown that this model can be used to study climate variability over the study area (Fig. 1). Detailed description of the model and relevant references are provided by the aforementioned studies. Table 1 summarizes the different parameterizations used.

RegCM model is set up with the centre longitude $7.5^{\circ} \mathrm{E}$, the centre latitude $6.5^{\circ} \mathrm{N}$, resolution of $40 \mathrm{~km}$ and the top at $5 \mathrm{hPa}$. The model domain is shown in Fig. 1, as well as the study area and the two homogeneous sub-regions (zone 1 and zone 2) for more specific analysis. Zone 1 represents the Sahel region, while zone 2 is spanned around the Congo basin with bimodal rain regime. Emphasis in the model results was made in December-January-February (DJF) and July-August-September (JAS) periods. These refer to the two main seasons over the zones 1 and 2. We have simulated six full years from January 2001 to December 2006 and for each of these years, two sets

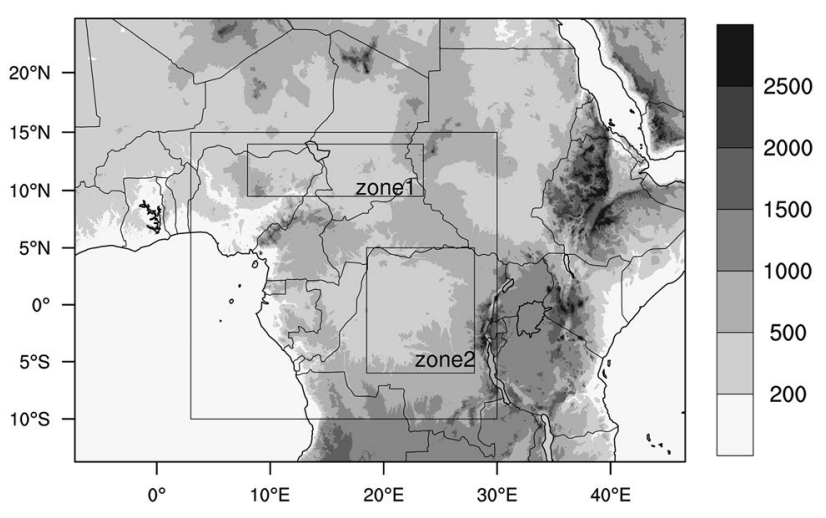

Fig. 1 Surface elevation $(\mathrm{m})$ of the simulation domain encompassing the study area indicated by the big box. The two small boxes indicate the two sub-regions, zone $1\left(9.5^{\circ}-14^{\circ} \mathrm{N}, 8^{\circ}-23.5^{\circ} \mathrm{S}\right)$ and zone $2\left(6^{\circ} \mathrm{S}-5^{\circ} \mathrm{N}, 18.5^{\circ} \mathrm{E}-28^{\circ} \mathrm{E}\right)$ for which the emphasis of the model results has been done 
Table 1 Summary of model's parameterizations

\begin{tabular}{ll}
\hline Model aspects & Parameterizations \\
\hline Dynamics & $\begin{array}{c}\text { Hydrostatic, } \sigma \text {-vertical } \\
\text { coordinate [15] } \\
\text { Radiative transfer }\end{array}$ \\
PBL & Modified CCM3 [25] \\
Cumulus convection & Godified Holtslag [20] \\
& Arakawa and Schu- \\
Land surface & bert closure [3] \\
Ocean fluxes & BATS [10] \\
\hline
\end{tabular}

of experiments (hereafter referred to as Exp and ExpA, respectively) were conducted. The first year of each experiment is discarded as spin-up and therefore is not used in the analysis. Exp does not include aerosol calculations, while ExpA accounts for aerosol (both natural and anthropogenic) calculations with radiative interactions which allow us to capture the aerosols diurnal impact. ExpA includes all kinds of the aerosols existing in RegCM4.4 (Sulphate, black and organic carbon, dust, and sea salt).

\subsection{Data}

Several data sets have been used to achieve our objective. These are classified into two categories: model input data set and model evaluation data set.

\subsubsection{Model input data set}

We use as initial boundary conditions the European Centre for Medium-Range Weather Forecasts (ECMWF) ReAnalysis (ERA-Interim) $1.5^{\circ}$ gridded [9]. ERA-Interim data set combines observations from satellites and groundbased meteorological networks and has a 6-hourly temporal resolution (00:00, 06:00, 12:00 and 18:00 UTC). Here, the variables used are sea surface temperature (SST), air temperature, geopotential height, relative humidity and horizontal wind component. We use also as RegCM input data set the 2 min resolution Global Land Cover Characteristics [36] and GTOPO topography data for the global terrain and land use. The input data set for the aerosols is the Representative Concentration Pathway (RCP) data set. RCP can be easily downloaded via the link http://clima -dods.ictp.it/regcm4/AERGLOB/. We use the standard dust scheme with four dust bins scheme included in RegCM4.

\subsubsection{Model validation data set}

Aerosol loading is characterized by aerosol optical depth (AOD). To validate the model AOD for our domain of interest, we make use of data from the MODerate resolution
Imaging Spectroradiometer (MODIS) which is onboard the NASA-EOS TERRA (morning orbit) and AQUA (afternoon) satellites [4, 21]. Here, the level-3 atmospheric monthly global products (since 2000 for TERRA and 2002 for AQUA) at the $1^{\circ} \times 1^{\circ}$ resolution which take into account all types of aerosols are used. The model diurnal precipitation is compared with the 3-hourly Tropical Rainfall Measuring Mission (TRMM) version 6 data 3B42 [21]. Its spatial resolution is $0.25^{\circ} \times 0.25^{\circ}$ latitude by longitude.

\subsection{General process}

Data from each 24-h period is fitted to diurnal harmonics to obtain both the diurnal amplitude and phase based on hourly RegCM outputs. In fact, harmonic analysis technique $[2,43,51]$ is a decomposition of a periodic function of a time series into a sum of trigonometric functions. A diurnal variation of precipitation $\widehat{P}(h)$ at hour $h$ can be represented by the summation of sinusoidal harmonics as:

$\widehat{P}(h)=\bar{P}+H_{k}(h)+$ residual,

where $\bar{P}$ is the daily mean value of $\widehat{P}(h)$ and the residual contains the higher-order harmonics of the daily variation. $H_{k}(h)$ is the harmonics and can be written as follows:

$H_{k}(h)=\sum_{k} A_{k} \cos \left(\frac{2 \pi^{\cdot} k h}{24}-\phi_{k}\right)$.

In Eq. 2, $A_{k}$ and $\phi_{k}$ are the amplitude and phase for the $k$ th harmonic, respectively. $k$ is the frequency or number of times the harmonic curve is repeated in $24 \mathrm{~h}$, also known as the harmonic number. $k=1$ for diurnal cycle, and therefore, the diurnal harmonic is $H_{1}(h)$. To determine the amplitude and phase (also interpreted as the time of maximum precipitation) of the diurnal cycle, we make use of the Fourier analysis.

\section{Results and discussion}

This section examines the potential impacts of aerosols on the diurnal cycle of precipitation. But, before this investigation, it is crucial to analyse the aerosols distribution from the model and MODIS data.

\subsection{Aerosols distribution}

We turn our attention on how well the model can reproduce aerosols over CA, compared to the MODIS data. Aerosols load is examined in term of AOD. According to two pathways of the light extinction, AOD can be discriminated in the sum of absorption $A O D$ and scattering $A O D$, 
and describes dimming of sunlight by aerosols burden. In the present study, our attention is made on total aerosols which include both natural and anthropogenic components, respectively. The first component in our study region can include dust aerosols, while the second component comes from fossil fuel and biomass burning, traffic, power plant, agriculture and industries.

Figure 2 depicts the seasonal mean aerosol optical depth from RegCM and MODIS. During DJF, the general pattern seems to be the same for RegCM aerosol simulation (Fig. 2a) and MODIS total AOD retrieval (Fig. 2c), even though the magnitudes are generally high for MODIS. During JAS, MODIS shows a distinct aerosol feature confined to a latitudinal belt between $10 \mathrm{~S}$ and $0 \mathrm{~S}$ (Fig. 2d) like to correspond to area of biomass burning located in zone 2 in the Congo basin region. In this area, a great amount of these aerosols certainly comes from man-made activities as shown in Fig. $2 f$. It is worth mentioning that the MODIS fine mode aerosols are usually used as anthropogenic component of MODIS total AOD retrievals. Discrepancies between model and MODIS $A O D$ over the region under the latitude $5 \mathrm{~N}$ could be due
Fig. 2 Seasonal mean aerosol optical depth from a, b RegCM, c, d MODIS total AOD and $\mathbf{e}, \mathbf{f}$ MODIS fine mode
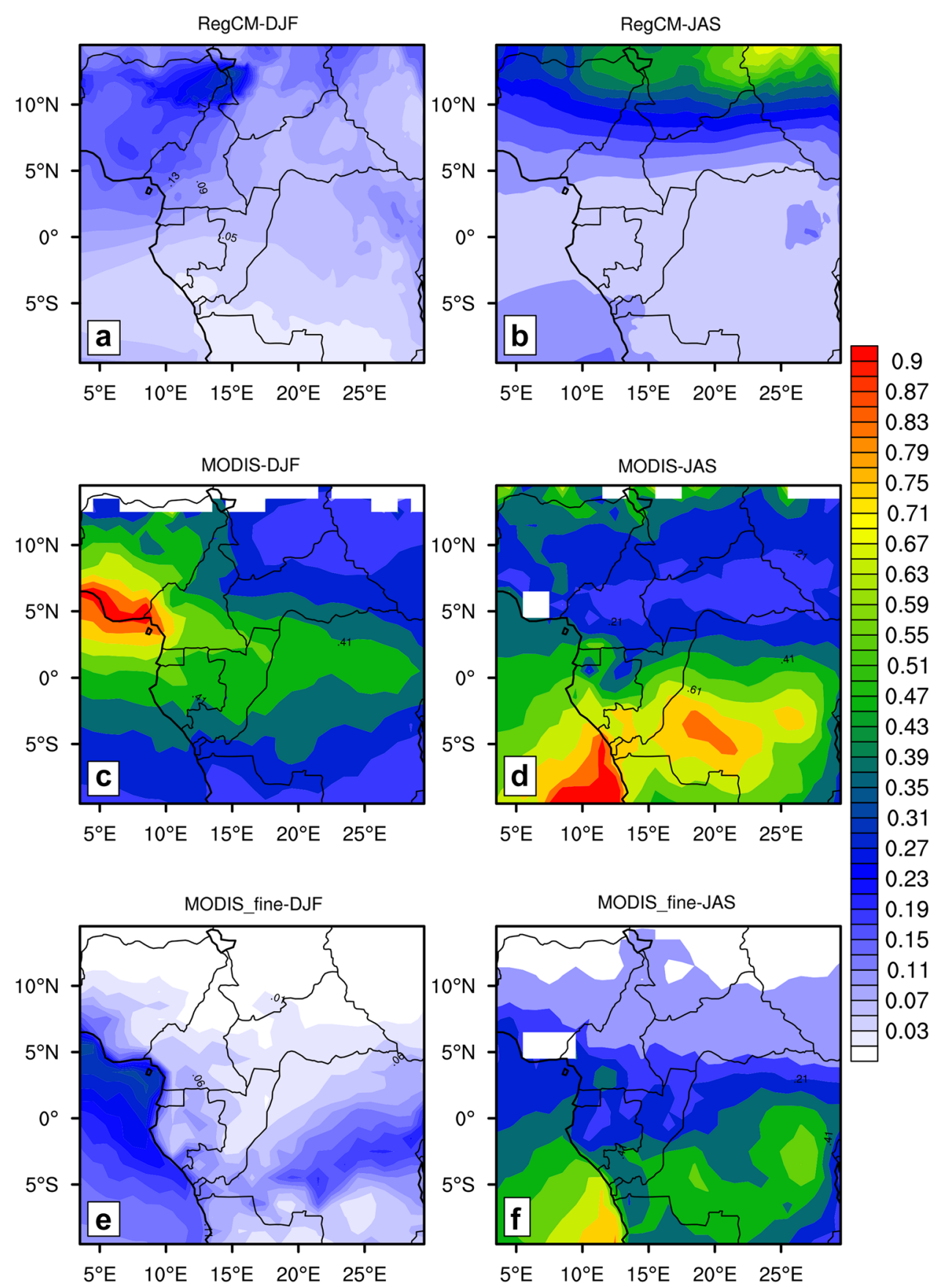
as reported in Malavelle et al. [33] by the fact that the satellite observations provide instantaneous information on the integrated and transported biomass burning aerosol, while RegCM AOD is provided for regular emissions all day long that could cumulate wherever transport is inefficiently resolved. As pointed out by Sayer et al. [41], because the samplings of models and satellite are very different, decision about data selection and aggregation may cause on monthly timescales regional differences in model AOD (Fig. 3). This figure shows the mean monthly AOD from MODIS satellite observations (total and fine modes) and model simulations. It is worth noticing that the MODIS fine mode is generally dedicated to anthropogenic aerosols. Indeed, over zone 1 , anthropogenic aerosols are insignificant compared to dust emissions (Fig. 3b). Thus, the aerosols effect over this region can be attributed to dust emissions. In parallel, RegCM performs well AOD during JAS over the northern part of CA encompassing zone 1 characterized by an occurrence of dust aerosols loading coming from the Sahelian region in West Africa. As it can be seen in Fig. $2 d$, MODIS retrieval shows maximum values in the gulf of Guinea around $3^{\circ} \mathrm{S}$ in JAS and $5^{\circ} \mathrm{N}$ in DJF. As already reported in Sayer et al. [41], possible causes could be related to the pixel cloud contamination. Overall, our results indicate that the simulated AOD is underestimated compared to MODIS total AOD retrieval. This underestimation can be related to not only the inaccurate model transport of dust aerosol from northern part to the southern part of the study region, but also to the possible underestimation of biomass burning aerosols over the southern part of CA in the Congo basin encompassing zone 2. Indeed, Sayer et al. [39] also show in RegCM outputs and underestimation of dust aerosol amount at locations far from the sources.

\subsection{Simulated and TRMM diurnal precipitation}

We examine in this stage of our study how well RegCM4.4 (Exp) can reproduce diurnal precipitation over CA compared to TRMM observations. Figure 4 presents how much the daily precipitation from model and TRMM can be explained by the first harmonic for DJF and JAS seasons. In general, regardless of the seasons, the daily precipitation from the first harmonic accounts for at least $80 \%$ of the daily variance over the rainy area. This result is not only true for model simulations (Fig. 4a, b), but also for the TRMM data set (Fig. 4c, d). This suggests that the first harmonic can represent the main characteristic of the observed daily precipitation, and therefore it can be used as a tool to measure the diurnal precipitation over the domain of interest.

Figure 5 shows the amplitude and phase in Local Solar Time at the maximum (LST is $1 \mathrm{~h}$ ahead UTC in Cameroon) of diurnal precipitation for experiment Exp and TRMM. The general pattern of the amplitude is reasonably well reproduced in DJF as well as in JAS as shown in Fig. 6. During this last season, locations of the peaks in Exp are well correlated by those found in TRMM product, even though the magnitude is different from a place to another. This difference can reach $-20 \%$ in the high lands of Cameroon and $+20 \%$ around Chad and Sudan borders. This suggests that the topography plays an important role in diurnal precipitation as mentioned in Vondou et al. [48]. Conversely, the model usually shows a systematic bias in the phase of the diurnal cycle consisting of an earlier placement of the amplitude (with a lag time of $3 \mathrm{~h}$ or more) of daily precipitation time (Fig. 7). As pointed out by Diro et al. [11], this bias is probably related to other components of the RegCM4.4 physics, most likely involving the deep convection schemes. In addition, the grid resolution of RegCM4.4 simulation used in the present study could be insufficient in order to properly resolve the geographic features and

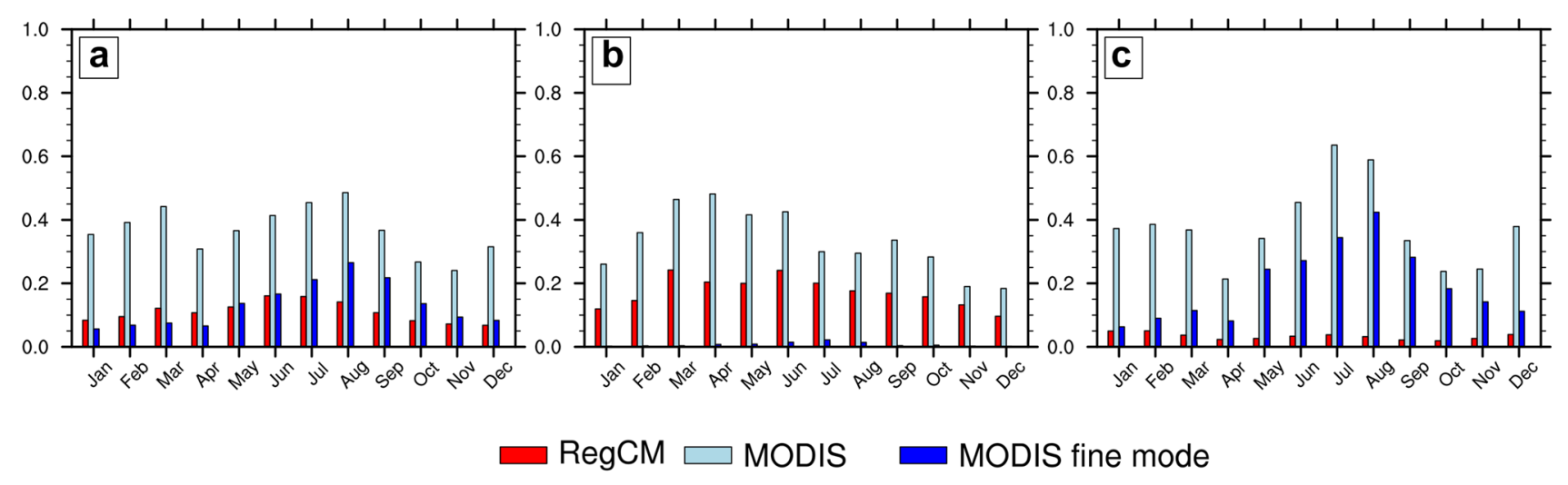

Fig. 3 Annual cycle of aerosol optical depth from RegCM and MODIS (total and fine modes) for $\mathbf{a}$ the whole domain, $\mathbf{b}$ zone 1 and $\mathbf{c}$ zone 2 
Fig. 4 Percentage of variance explained by the diurnal cycle (first harmonic) for DJF (first column) and JAS (second column) from $\mathbf{a}, \mathbf{b}$ Exp, and $\mathbf{c}$, d TRMM
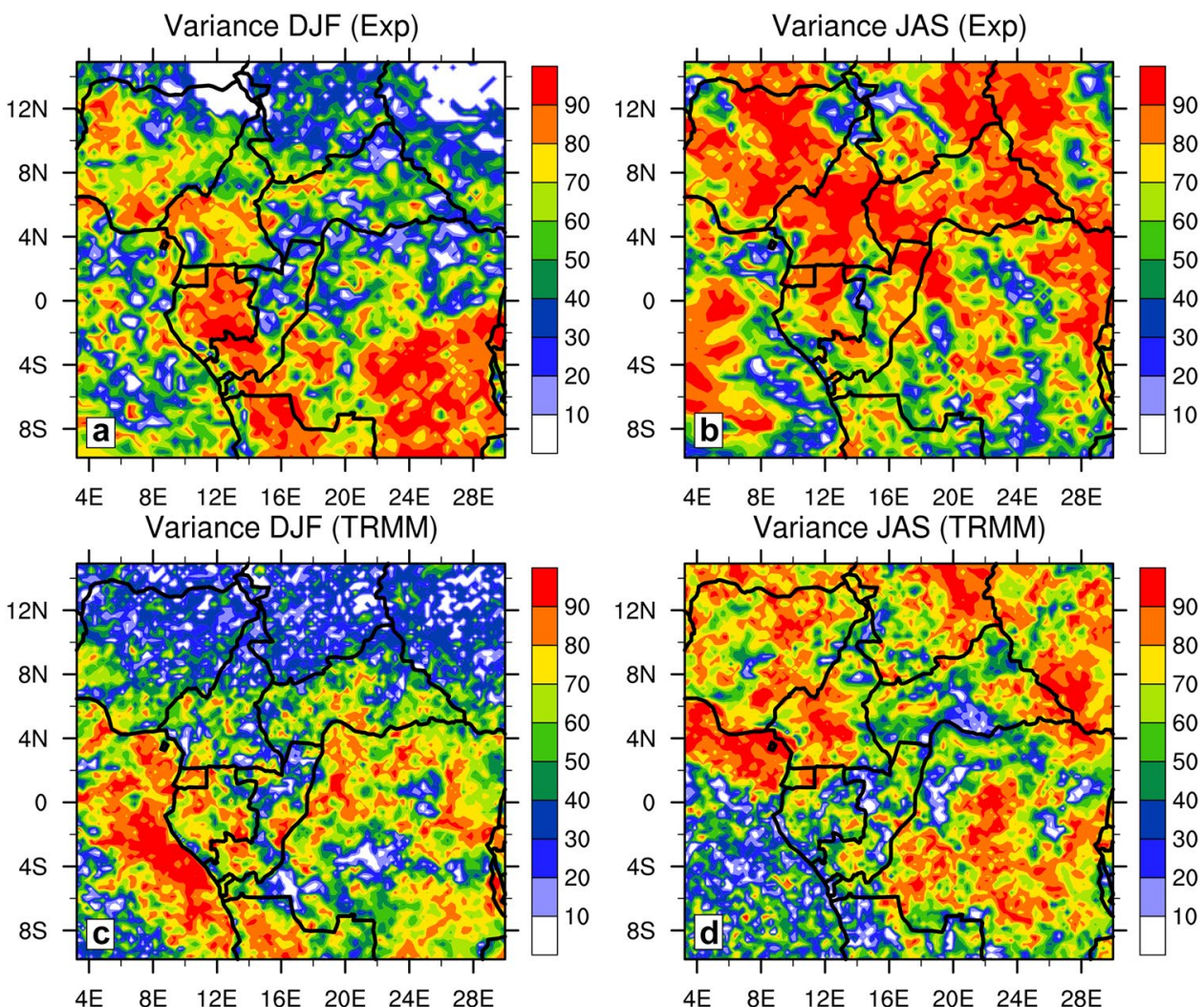

various associated climatic phenomena evolving in the subgrid scale. Some previous studies $[19,40]$ have suggested that a higher resolution model simulation with a cloud resolving scheme better matches observations with reality. Another explanation of this discrepancy between RegCM4.4 and TRMM is that this last product encompasses precipitation estimates from infrared spectrum, since Lin et al. [32] have shown that the timing between the maximum surface precipitation and the minimum outgoing longwave radiation or coldest cloud top surface which is the basis of infrared estimates in TRMM 3B42 can have a lag time of $2-3 \mathrm{~h}$. The diurnal evolution of precipitation shown in Fig. 7 reveals that the model represents the general pattern, but always with very low values peculiarly in the late afternoon. In fact, because of longer life cycle of mesoscale convective system, the diurnal cycle of precipitation peaks in the evening even though convective intensity peaks in the late afternoon over Africa as reported by Nesbitt and Zipser [35]. Overall, the RegCM4.4 can really be used to study diurnal precipitation over CA, and it is therefore crucial to investigate what can be the potential effects of aerosols on this precipitation.

\subsection{Aerosols influence on diurnal precipitation}

The remaining question from the previous analysis is, what may be the impacts of aerosols on the diurnal precipitation over CA? To understand the impact of aerosol on the diurnal precipitation, we analyse difference between ExpA and Exp. Having established the performance of the model diurnal cycle of precipitation, we now focus on the potential impact of aerosols on the amplitude and phase of diurnal precipitation. Figure $8 \mathrm{a}$, c shows the aerosols inducing changes in amplitude of diurnal precipitation during DJf and JAS seasons, respectively. The corresponding changes in phase are presented in Fig. $8 b, c$. Over the rainy area (domain under latitude 0 encompassing zone 2 during DJF and the domain above latitude 0 encompassing zone 1 during JAS), amplitude of precipitation is systematically affected by either a reduction or an increase by up to $\pm 20 \%$ and $\pm 40 \%$ during DJF and JAS, respectively. The phase is not really affected during both seasons over the major part of rainy area. The changes in amplitude are certainly due to the fact that precipitation often occurs between early afternoon and night (Fig. 5) where both natural and anthropogenic emissions reach their peak. In addition, high precipitation bias recorded during JAS reveals the presence of dust aerosol transported by the West African monsoon. In fact, the amplitude of both incoming longwave and shortwave radiations is reached early afternoon (Figs. 9, 10, 11, 12). Indeed, more the land surface is heated, more aerosols (especially dust aerosols) are emitted and transported from a location to another over the study area. Figure $8 \mathrm{c}$ shows a strong increase in 
Fig. 5 Spatial distribution of a, c amplitudes of diurnal cycle of precipitation (in $\mathrm{mm}$ ) from Exp and TRMM for DJF, $\mathbf{b}, \mathbf{d}$ solar local time at the maximum (phase). e, $\mathbf{f}$ amplitude and phase differences. Negative phase difference indicates that the model precipitation peaks earlier than TRMM. The dot shading indicates areas in which the difference between Exp and TRMM is statistically significant at the $95 \%$ confidence level according to a two-tailed $t$ test
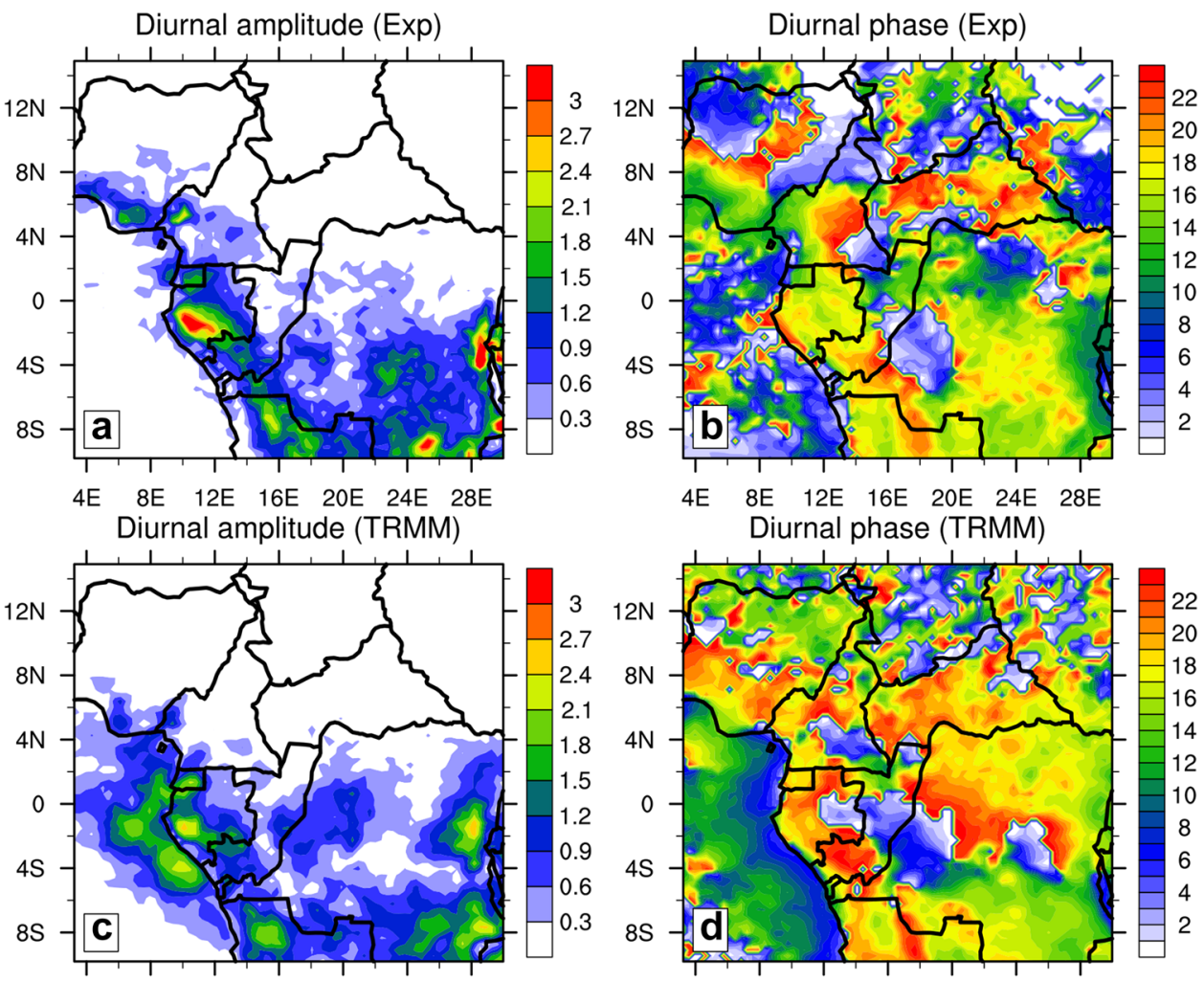

4E $\quad 8 \mathrm{E} \quad 12 \mathrm{E} \quad 16 \mathrm{E} \quad 20 \mathrm{E} \quad 24 \mathrm{E} \quad 28 \mathrm{E}$ Amplitude difference (Exp-TRMM)
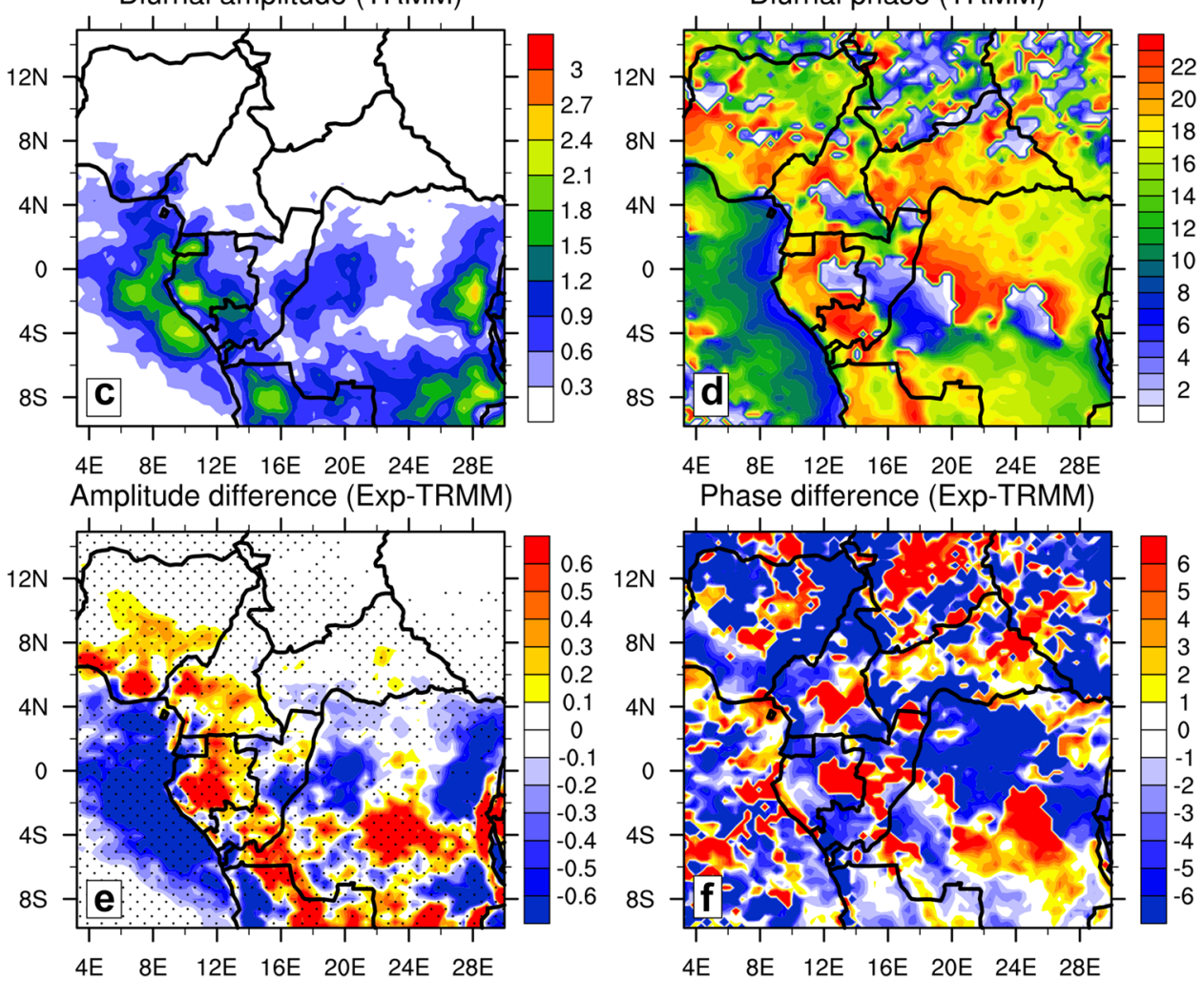

the amplitude of precipitation by more than $1 \mathrm{~mm}$ over Adamaoua Plateau and west regions in Cameroon during JAS. This result can be an indicator for the significant effects of mountain on the increase in only precipitation amplitude, since the phase is not really affected (Fig. 8d). In fact, these higher elevation regions found to favour the generation of long-lived mesoscale convective systems [37] have recorded the highest precipitation amplitude over the study area (Fig. 6). Therefore, mesoscale convection can be associated with the role of aerosols in the amplitude of precipitation. To elucidate some reasons for the different responses in the diurnal precipitation, the downwelling fluxes are analysed.

Figure 9 shows the DJF diurnal amplitude and phase of surface downwelling shortwave (SW) flux in $\mathrm{W} \mathrm{m}^{-2}$ for both Exp and ExpA, respectively. The corresponding surface downwelling longwave (LW) is presented in Fig. 11. As expected, these figures show that (1) the maximum LW flux intensities are smaller than those of SW flux (approximately 6.3\%) and (2) the time corresponding to peak is around 1500 LST. These results are quite similar to those found during JAS (Figs. 10, 12). During DJF, aerosols-induced change in diurnal amplitude of precipitation is in phase with changes in both LW and SW downwelling flux. Since this finding is not applicable during $\mathrm{JAS}$, we can state that the aerosol inducing changes in diurnal precipitation amplitude during DJF is strongly related to the corresponding changes in downwelling flux. The reduction in the amplitude of diurnal downwelling SW radiative flux is observed almost all over the 
Fig. 6 Same as Fig. 5, but for JAS
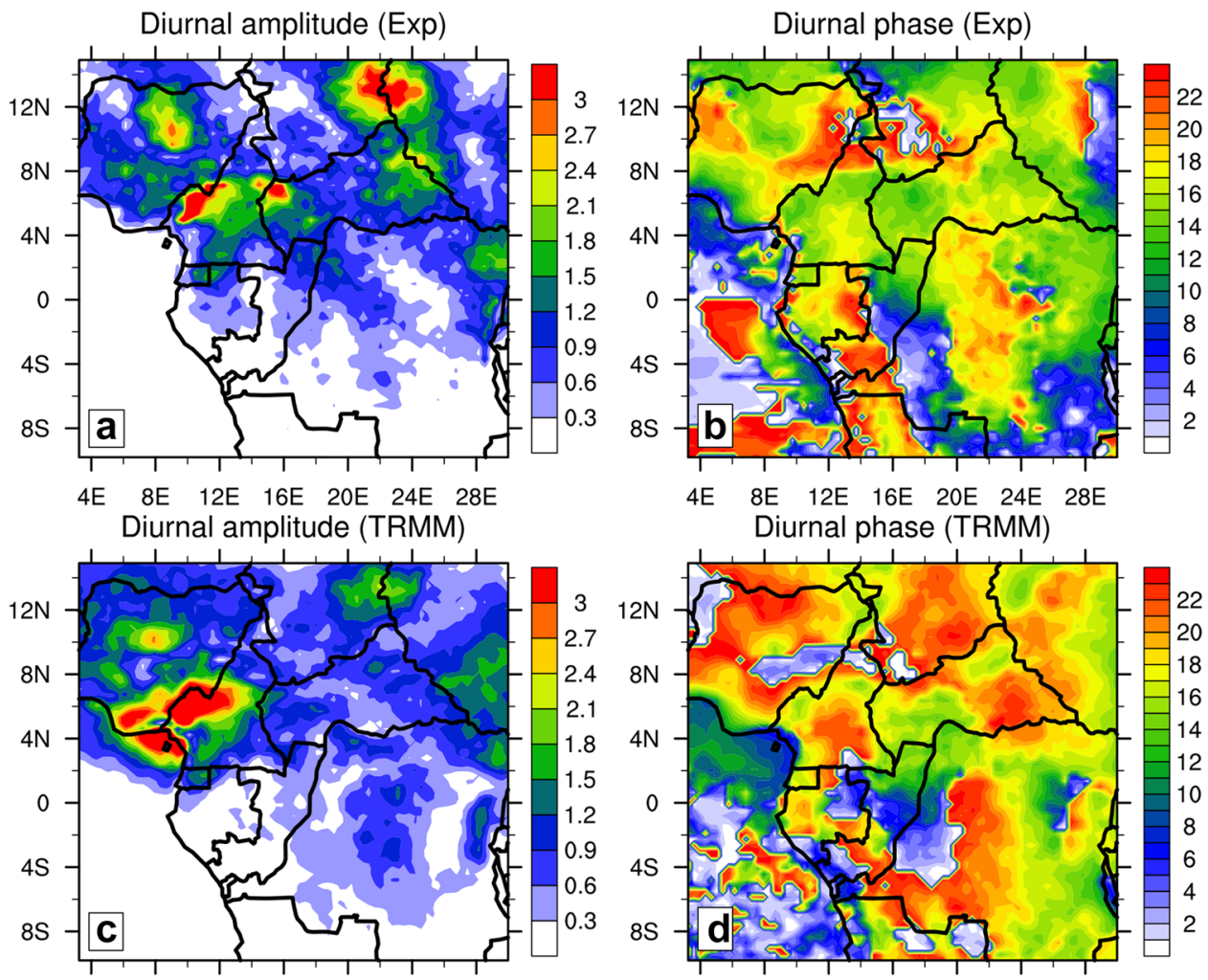

$\begin{array}{lllllll}4 \mathrm{E} & 8 \mathrm{E} & 12 \mathrm{E} & 16 \mathrm{E} & 20 \mathrm{E} & 24 \mathrm{E} & 28 \mathrm{E}\end{array}$

Amplitude difference (Exp-TRMM)

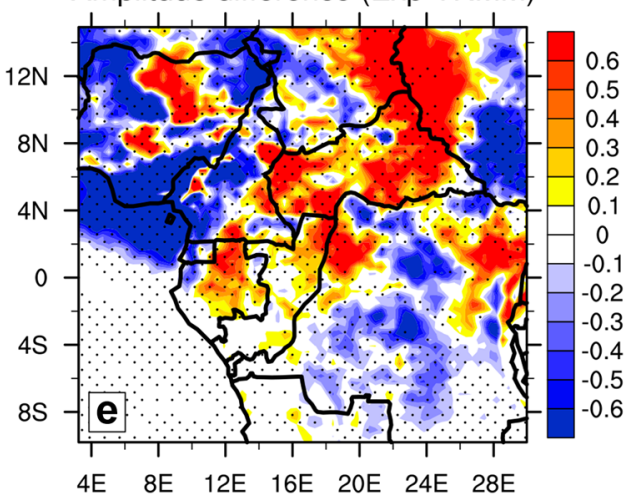

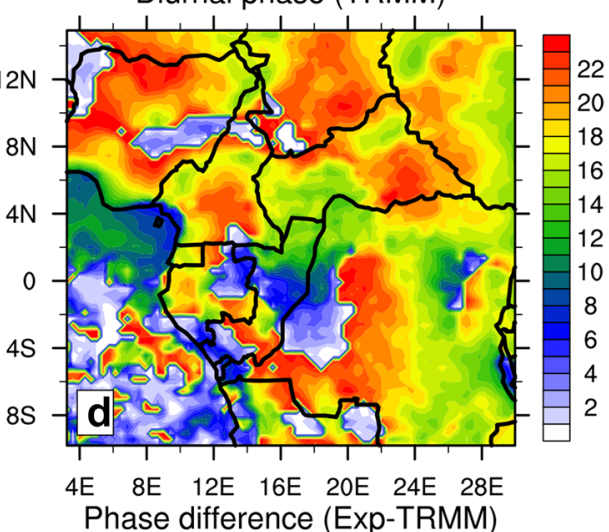

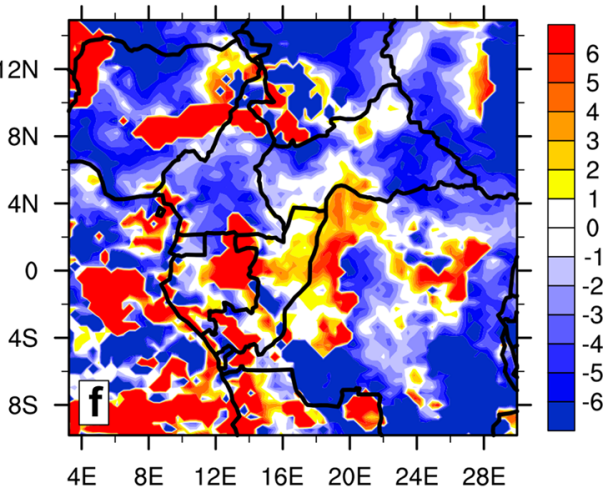

rainy area during both DJF and JAS. This can explain the role of scattering and absorption of solar radiation by aerosols in the reduction in precipitation diurnal amplitude. In fact, during daytime, both scattering and absorption of solar radiation reduce the shortwave radiation reaching the surface of the Earth. The absorption of solar radiation by aerosols warms the lower to mid-troposphere where the aerosols are found. Consequently, aerosols cool the Earth's surface and warm the atmosphere, thereby increasing the atmospheric stability below the aerosols levels and reducing the daytime precipitation. As it is illustrated in Figs. 9f, 10, 11 and 12f, no systematic changes are found in the phase of diurnal downwelling radiative flux. This result is consistent with previous modelling simulations results such as in Kim et al. [26].

\section{Conclusion}

The objective of the present study was to examine the influence of aerosols on the diurnal precipitation over central Africa (CA). Two sets of 6 years from January 2001 to December 2006 were simulated using the ICTP regional climate model RegCM4.4 at 40-km horizontal grid. For each of the simulated years, two sets of experiments (Exp and $\operatorname{ExpA}$ ) were conducted. The first year of each experiment is discarded as spin-up and therefore is not 
Fig. 7 DJF (first column) and JAS (second column) diurnal cycle of precipitation from TRMM product and model simulations (Exp and ExpA) for $\mathbf{a}, \mathbf{b}$ whole domain, $\mathbf{c}, \mathbf{d}$ zone 1 and e, $\mathbf{f}$ zone 2 . The vertical bars denote the error assessment of the 3-h mean TRMM data
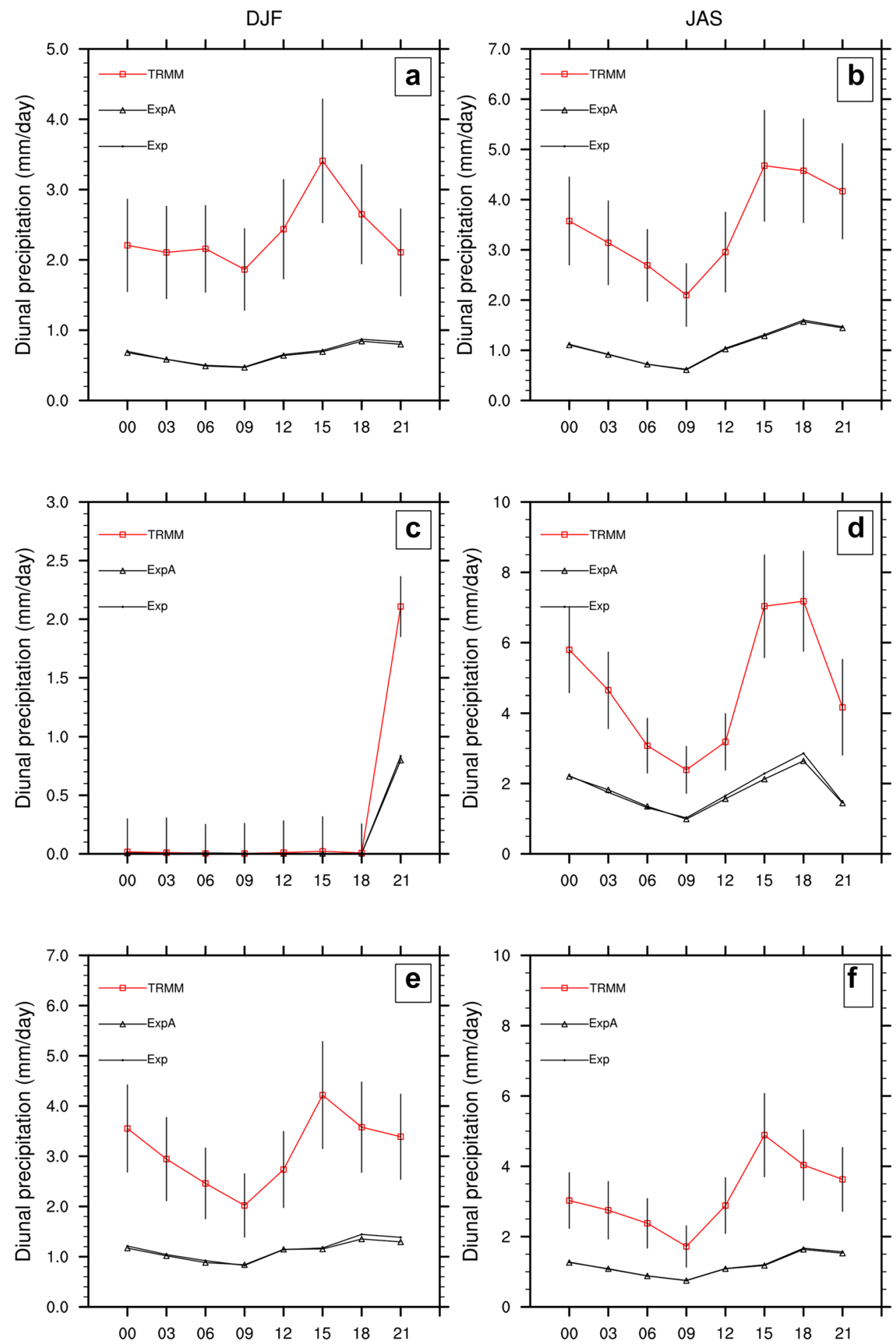

used in the analysis. Exp does not include aerosol calculations, while ExpA accounts for aerosol (both natural and anthropogenic) calculations with radiative interactions which allow us to capture the aerosols diurnal impact. Two seasons, December-January-February (DJF) and July-August-September (JAS) as well as two homogeneous sub-regions (zone 1 and zone 2 ) are identified for more specific analysis. Zone 1 represents the Sahel region, while zone 2 is spanned around the Congo basin with bimodal rain regime.

RegCM performs well AOD during JAS over the northern part of $C A$ encompassing zone 1 characterized by an occurrence of dust aerosols loading coming from the Sahelian region in West Africa. Our results indicate that 
Fig. 8 DJF and JAS aerosols induce changes (ExpA-Exp) on $\mathbf{a}, \mathbf{c}$ diurnal amplitude and $\mathbf{b}, \mathbf{d}$ phase of the diurnal precipitation. The dot shading indicates areas in which the difference between ExpA and Exp is statistically significant at the $95 \%$ confidence level according to a two-tailed $t$ test
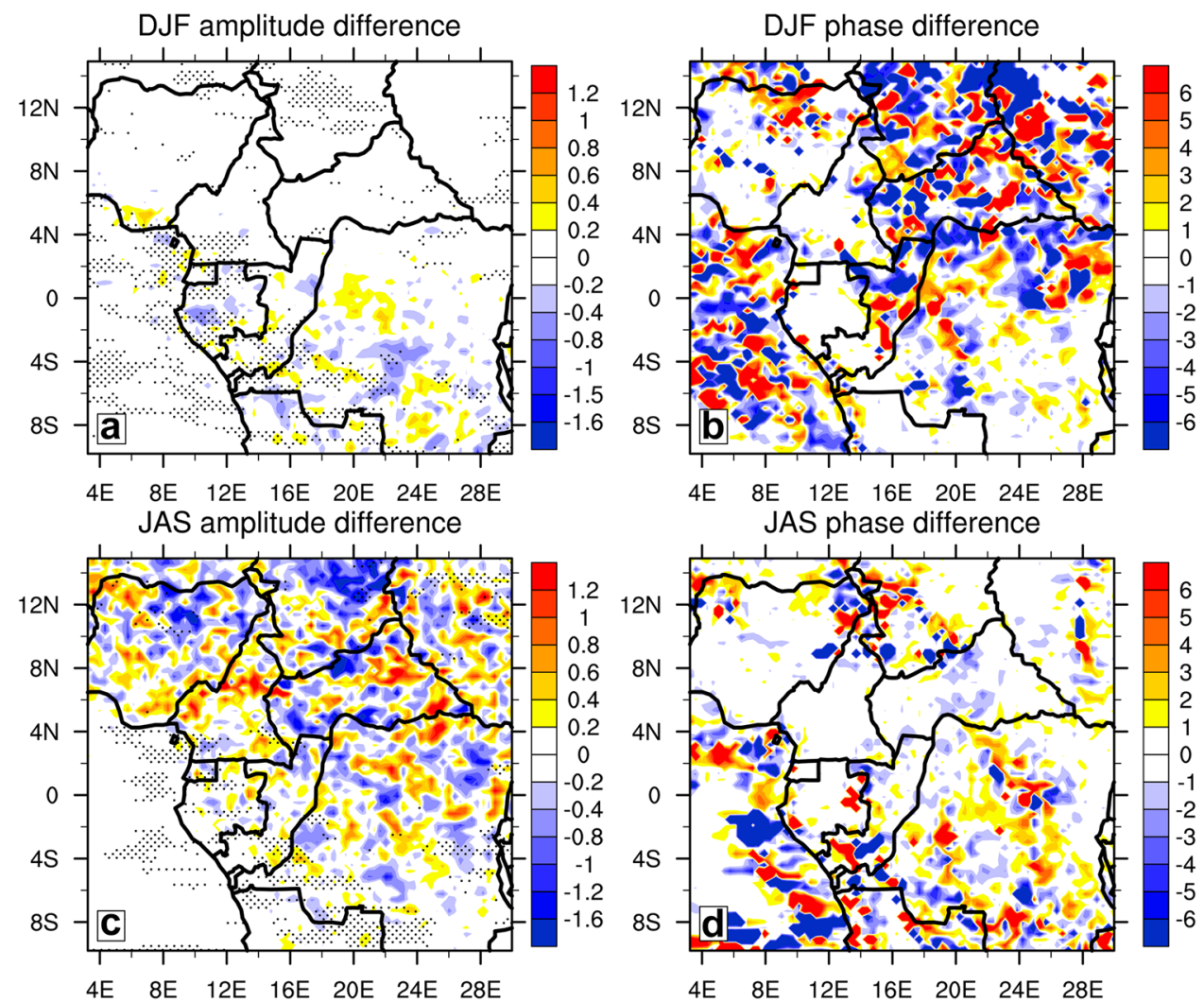

the simulated AOD is underestimated compared to MODIS total AOD retrieval. This underestimation can be related to not only the inaccurate model transport of dust aerosol from northern part to the southern part of the study region, but also to the possible underestimation of biomass burning aerosols over the southern part of CA in the Congo basin encompassing zone 2 .

The general pattern of diurnal cycle is reasonably well reproduced compared to the TRMM 3B42 products. RegCM4.4 usually shows a systematic bias in the phase of the cycle consisting of an earlier placement of the amplitude (with a lag time of $3 \mathrm{~h}$ or more) of daily precipitation time. Overall, the RegCM4.4 can really be used to study diurnal precipitation over $\mathrm{CA}$, and it is therefore crucial to investigate what can be the potential effects of aerosols on this precipitation.
Over the rainy area, amplitude of precipitation is systematically affected by either a reduction or an increase by up to $\pm 20 \%$ and $\pm 40 \%$ during DJF and JAS, respectively. The phase is not really affected during both seasons over the major part of rainy area. The changes in amplitude are certainly due to the fact that precipitation often occurs between early afternoon and night where both natural and anthropogenic emissions reach their peaks. In addition, high precipitation bias recorded during JAS reveals the presence of dust aerosol transported by the West African monsoon. As a final remark, we would like to point out that a better understanding of the diurnal cycle, and its variability, will lead to better short-range forecasts. We plan to examine the dependency of the diurnal cycle simulated on the grid resolution of the model by comparing the present results with those from simulations with different fine spatial resolutions. 
Fig. 9 DJF diurnal amplitude and phase of surface downwelling shortwave flux in $W \mathrm{~m}^{-2}$ for $\mathbf{a}, \mathbf{b} \operatorname{Exp}$ and $\mathbf{c}, \mathbf{d}$ ExpA, and $\mathbf{e}, \mathbf{f}$ corresponding aerosols induce changes
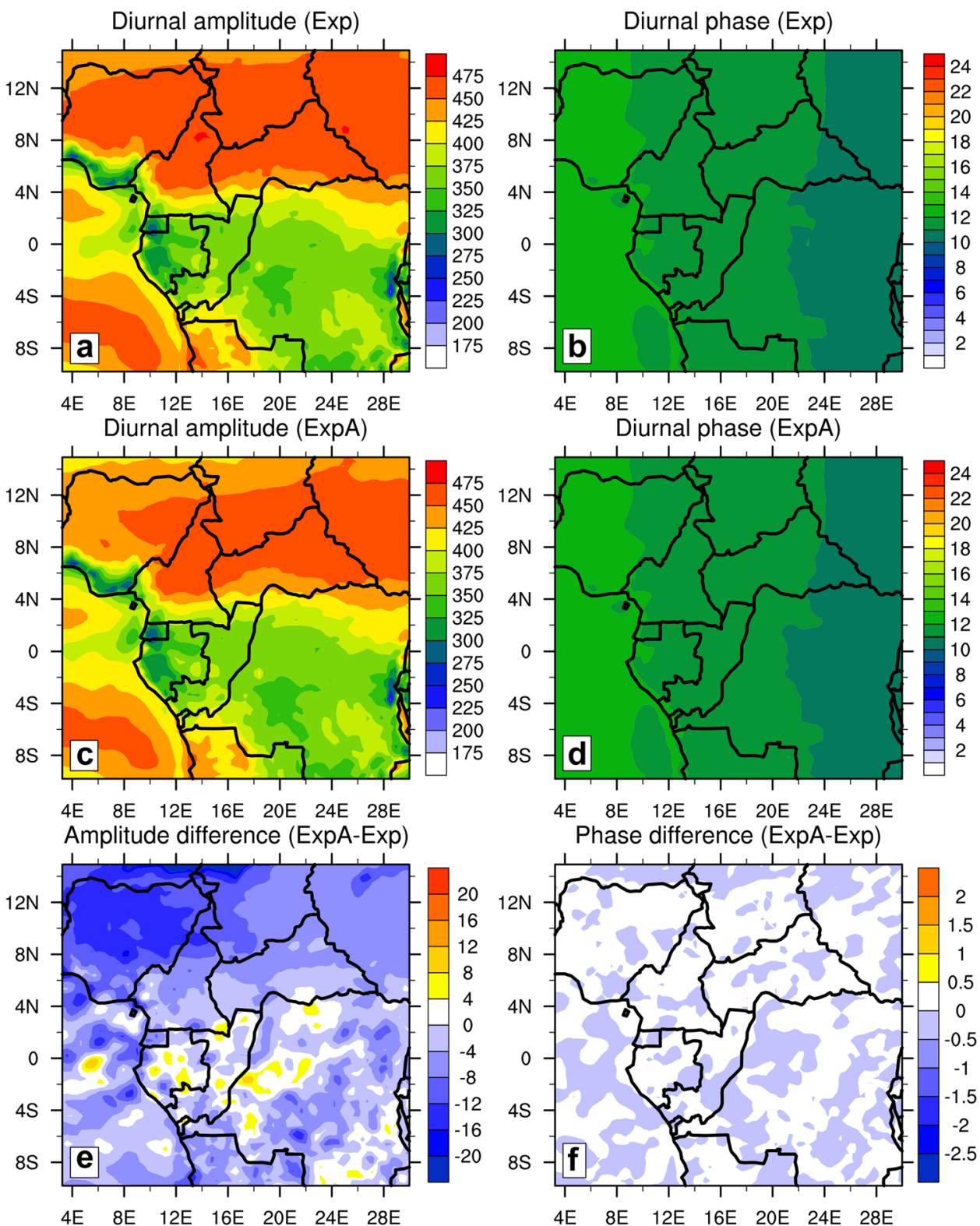
Fig. 10 Same as Fig. 9 but for JAS
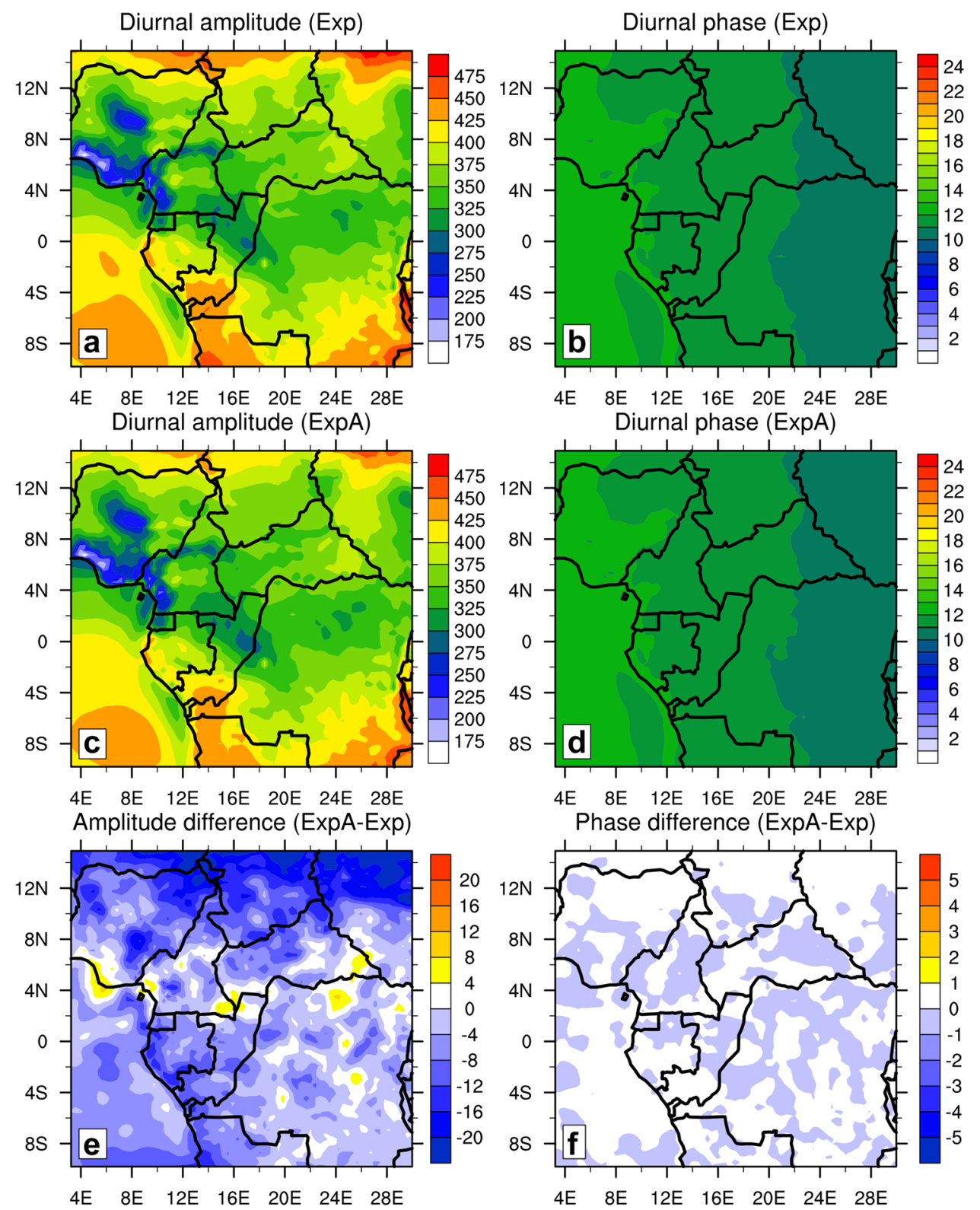
Fig. 11 DJF diurnal amplitude and phase of surface downwelling longwave flux in $\mathrm{W} \mathrm{m}^{-2}$ for $\mathbf{a}, \mathbf{b} \operatorname{Exp}$ and $\mathbf{c}, \mathbf{d} \operatorname{ExpA}$, and e, $\mathbf{f}$ corresponding aerosols induce changes
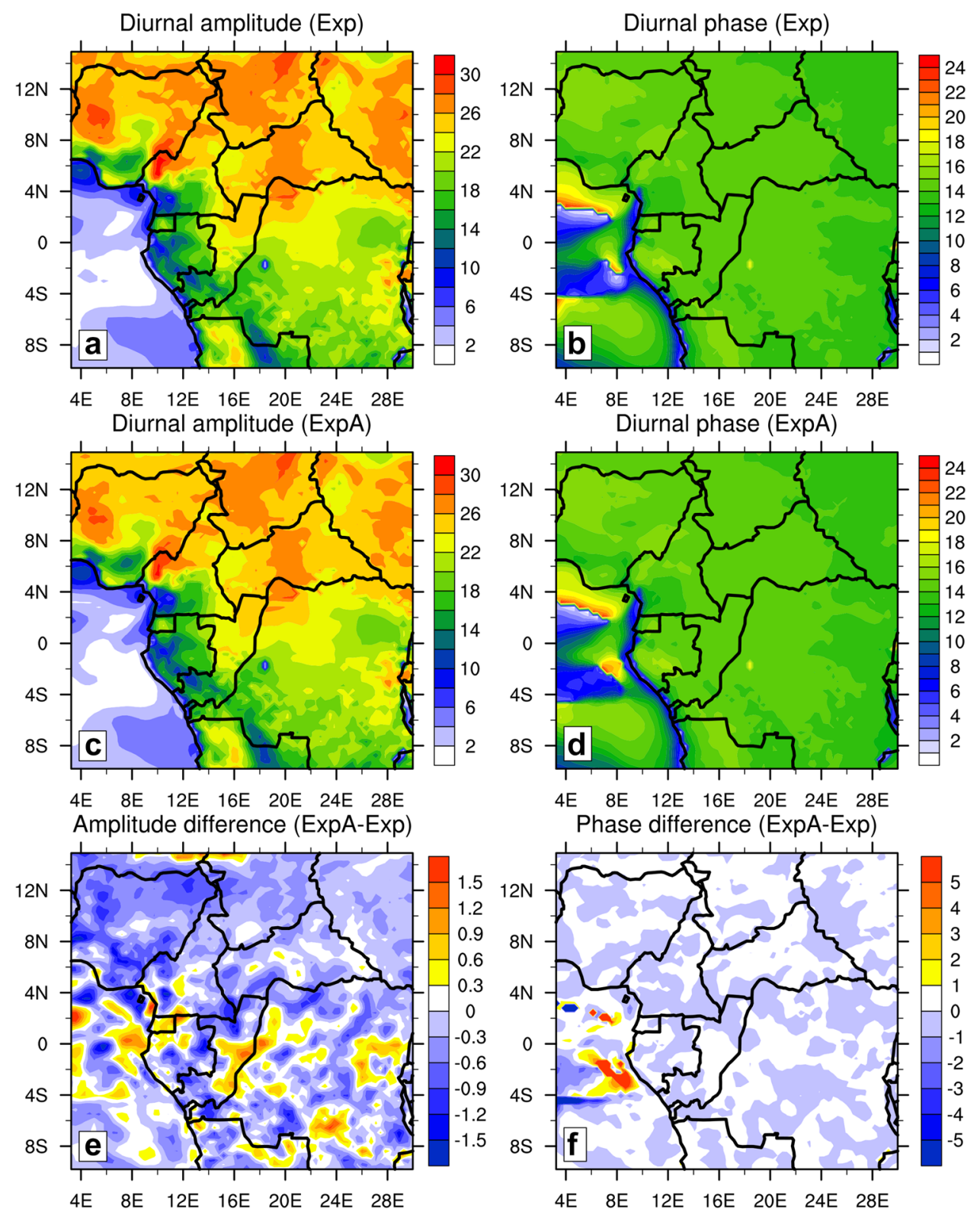
Fig. 12 Same as Fig. 11 but for JAS
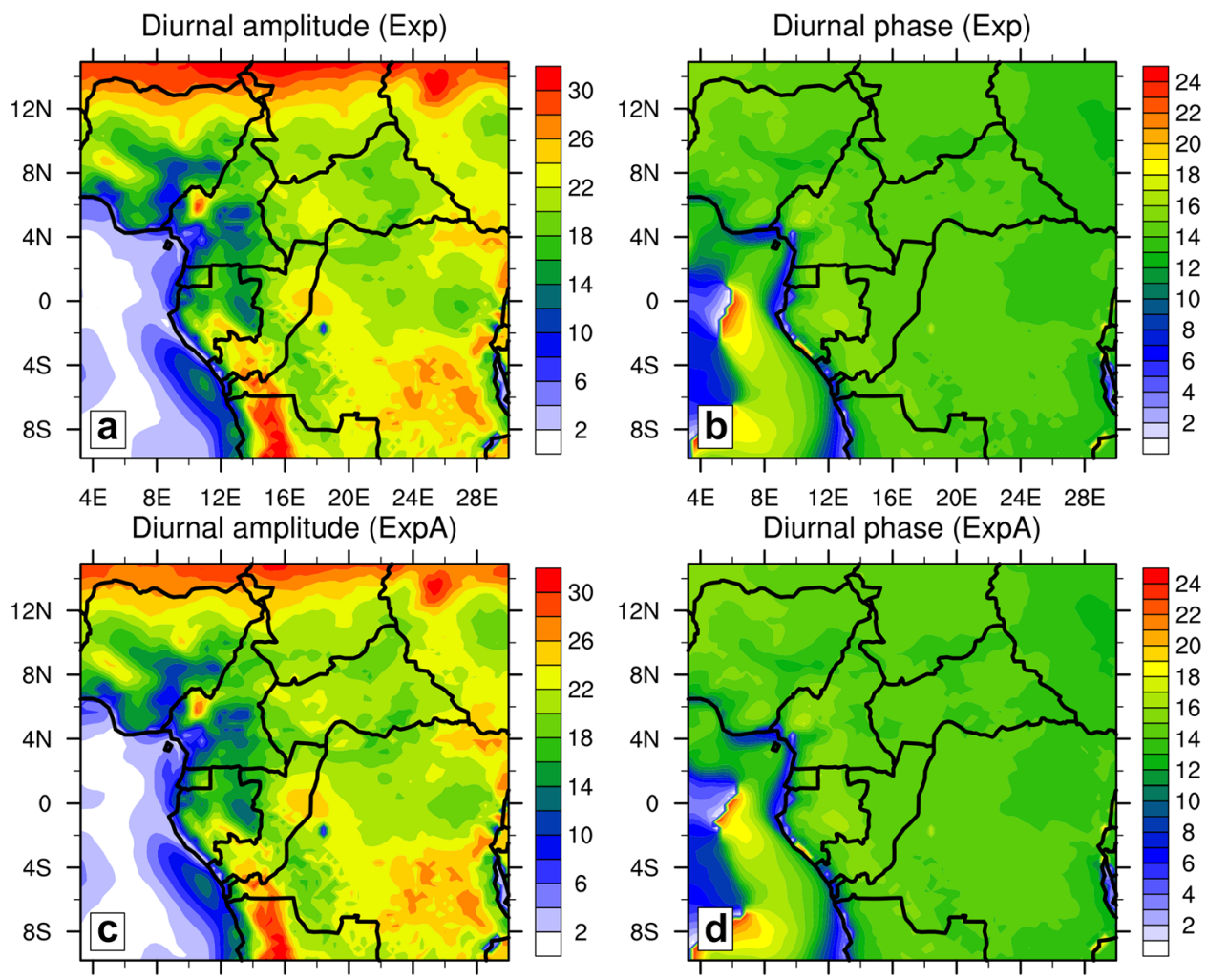

4E $\quad 8 \mathrm{E} \quad 12 \mathrm{E} \quad 16 \mathrm{E} \quad 20 \mathrm{E} \quad 24 \mathrm{E} \quad 28 \mathrm{E}$ Amplitude difference (ExpA-Exp)
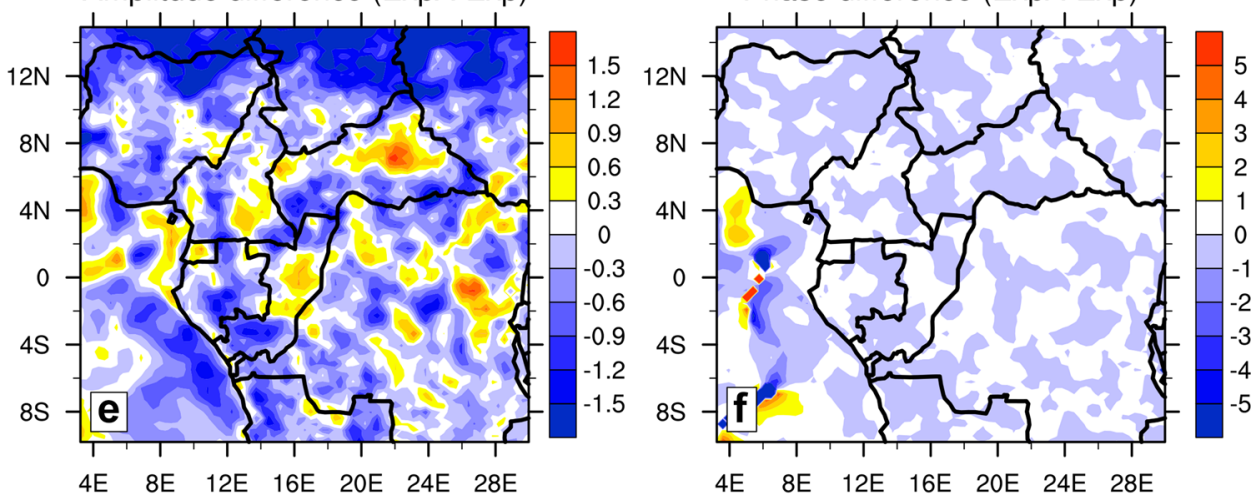

Acknowledgements The first author acknowledges C. V. Raman Fellowship and wishes to thank Dr. Sagnik Dey for his collaboration and useful discussions. The authors thank DST-FIST grant for supporting HPC facility at IIT Delhi (SR/FST/ESII-016/2014). A. J. Komkoua Mbienda is grateful to Dr. Erika Coppola and Dr. Filippo Giorgi of the Abdu Salam International Centre of Theoretical Physics (ICTP) who provided a number of insights regarding the RegCM model during his last stay in Trieste (Italy) in April 2018. We also acknowledge the two anonymous reviewers for their helpful comments.

\section{Compliance with ethical standards}

Conflict of interest On behalf of all authors, the corresponding author states that there is no conflict of interest.

\section{References}

1. Anderson CJ, Arritt RW, Kain JS (2007) An alternative mass flux profile in the Kain-Fritsch convective parameterization and its seasonal precipitation. J Hydrometeorol 8:1128-1140. https:// doi.org/10.1175/JHM624.1

2. Angelis CF, McGregor GR (2004) Diurnal cycle of rainfall over the Brazilian Amazon. Clim Res 26:139-149

3. Arakawa A, Schubert WH (1974) Interaction of a cumulus cloud ensemble with large-scale environment. J Atmos Sci 31:674-701

4. Banes WL, Pagano TS, Salomonson VV (1998) Prelaunch characteristics of the moderate resolution imaging spectroradiometer (MODIS) on EOS-AM1. IEEE Trans Geosci Remote Sens 36:1088-1100

5. Bell TL, Rosenfeld D, Kim KM, Lee MI, Hahnenberger M (2008) Midweek increase in U.S. summer rain and storm heights 
suggests air pollution invigorates rainstorm. J Geophys Res 113:D02209. https://doi.org/10.1029/2007JD008623

6. Chaboureau JP, Tulet P, Mari C (2007) Diurnal cycle of dust and cirrus over West Africa as seen from Meteosat Second Generation satellite and a regional forecast model. Geophys Res Lett 34:L02822. https://doi.org/10.1029/2006GL0227771

7. Collier JC, Bowman KP (2004) Diurnal cycle of precipitation in a general circulation model. J Geophys Res 109:D1705. https:// doi.org/10.1029/2004JD004818

8. Dai A, Trenberth KE (2004) The diurnal cycle and its depiction in the Community Climate Model. J Clim 17:930-951

9. Dee DP (2011) The ERA-Interim reanalysis: configuration and performance of the data assimilation system. Q J R Meteorol Soc 137:553-597. https://doi.org/10.1002/qj.828

10. Dickinson RE, Henderson-Sellers A, Kennedy PJ (1993) Biosphere-atmosphere transfer scheme (BATS) version 1e as coupled to the NCAR community climate model. Technical report, National Center for Atmospheric Research

11. Diro GT, Rauscher SA, Giorgi F, Tompkins AM (2012) Sensitivity of seasonal climate and diurnal precipitation over Central America to land and sea surface schemes in RegCM4. Clim Res 52:31-48. https://doi.org/10.3354/cr01049

12. Fowler HJ, Blenkinsop S, Tebaldi C (2007) Linking climate modelling to impacts studies: recent advances in downscaling techniques for hydrological modelling. Int J Climatol 27:1547-1578. https://doi.org/10.1002/joc.1556

13. Giorgi F, Coppola E, Solomon F, Mariotti L, Sylla MB, Bill X, Elguindi N, Diro T, Nair V, Giuliani G, Turuncoglu UU, Cozzini S, Guttler I, O'Brien A, Tawfik AB, Shalaby A, Zakey AS, Steiner AL, Stordal F, Sloan LC, Brankovic C (2012) RegCM4: model description and preliminary tests over multiple CORDEX domains. Clim Res 52:7-29

14. Giorgi F, Elguindi N, Cozzini S, Solmon F, Giuliani G (2015) Regional Climatic Model RegCM User's Guide Version 4.4. Technical report, ICTP, Trieste, Italy, p 579

15. Giorgi F, Marinucci MM, Bates GT (1993) Development of a second generation regional climate model (RegCM2). Part I: boundary layer and radiative transfer processes. Mon Weather Rev 121:2794-2813

16. Glasbey CA, Cooper G, McGechan MB (1995) Disaggregation of daily rainfall by conditional simulation from a point-process model. J Hydrol 165:1-9

17. Grell GA (1993) Prognostic evaluation of assumptions used by cumulus parameterizations. Mon Weather Rev 121:764-787

18. Gu Y, Liou KN, Jiang JH, Su H, Liu X (2012) Dust aerosol impact on the North Africa climate: a GCM investigation of aerosol-cloudradiation interactions using $\mathrm{A}$-Train satellite data. Atmos Chem Phys 12:1667-1679

19. Hohenegger $C$, Brockhaus $P$, Schar $C$ (2008) Towards climate simulations at cloud-resolving scales. Meteorol Z 17:383-394

20. Holtslag A, de Bruijn E, Pan HL (1990) A high resolution air mass transformation model for short-range weather forecasting. Mon Weather Rev 118:1561-1575

21. Huffman GJ, Bolvin DT (2013) TRMM and other data precipitation data set documentation. Technical report, Mesoscale Atmospheric Processes Laboratory, NASA Goddard Space Flight Center and Science Systems and Applications, Inc. Greenbelt

22. Karl TR, Trenberth KE (2003) Modern global change. Science 302:1719-1723. https://doi.org/10.1126/science.1090228

23. Katz RW, Parlange MB (1995) Generalizations of chain-dependent processes: application to hourly precipitation. Water Resour Res 31:1331-1341

24. Kaufman YJ, Koren I, Remmer LA, Rosenfeld D, Rudich Y (2005) The effect of smoke, dust and pollution aerosol on shallow cloud development over the atlantic ocean. Proc Natl Acad Sci 10(32):11207-112012
25. Kiehl J, Hack J, Bonan G, Boville B, Breigleb B, Williamson D, Rasch O (1996) Description of the NCAR Community Climate Model CCM3. Technical report, National Center for Atmospheric Research

26. Kim KM, Lau WK, Sud YC, Walker GK (2010) Influence of aerosol-radiative forcings on the diurnal and seasonal cycle of rainfall over West Africa and Eastern Atlantic Ocean using GCM simulation. Clim Dyn. https://doi.org/10.1007/s0038 2010-0750-1

27. Komkoua Mbienda AJ, Tchawoua C, Vondou DA, Choumbou P, Kenfack Sadem C, Dey S (2017) Impact of anthropogenic aerosols on climate variability over Central Africa by using a regional climate model. Int J Climatol 37:249-267. https://doi. org/10.1002/joc.4701

28. Komkoua Mbienda AJ, Tchawoua C, Vondou DA, Choumbou P, Kenfack Sadem C, Dey S (2017) Sensitivity experiments of the RegCM4 simulations to different convective schemes over Central Africa. Int J Climatol 37:328-342. https://doi. org/10.1002/joc.4707

29. Lau KM, Kim KM, Lee MI (2007) Characteristics of diurnal and seasonal cycles in global monsoon systems. J Meteorol Soc Jpn 85A:403-416

30. Lau KM, Kim KM, Sud YC, Walker GK (2009) A GCM study of the response of the atmospheric water cycle of West Africa and the Atlantic to Saharan dust radiative forcing. Geophys Ann 27:4023-4037

31. Lee MI, Shoulbert SD, Suarez MJ, Bell TL, Kim KM (2007) Diurnal cycle of precipitation in the NASA Seasonal to International Prediction Project atmospheric general circulation model. J Geophys Res 112:D1611. https://doi.org/10.1029/2006JD0083 46

32. Lin X, Randall DA, Fowler LD (2000) Diurnal variability of the hydrologic cycle and radiative fluxes: comparisons between observations and a GCM. J Clim 13:4159-4179

33. Malavelle F, Mallet M, Pont V, Liousse C, Solmon F (2011) Long-term simulations (2001-2006) of biomass burning and mineral dust optical properties over West Africa: comparisons with new satellite retrievals. Atmos Chem Phys Discuss 11:28587-28626

34. Mo KC, Schemm JK, Juang HMH, Higgins W (2005) Impact of the model resolution on the prediction of summer precipitation over the United States and Mexico. J Clim 36:3910-3927

35. Nesbitt SW, Zipser EJ (2003) The diurnal cycle of rainfall and convective intensity according to three years of TRMM measurements. J Clim 16:1456-1475

36. New M, Hulme M, Jones P (2000) Representing twentiethcentury space-time climate variability: part II: development of 1901-1996 monthly grids of terrestrial surface climate. J Clim 13:2217-2238

37. Ogungbenro SB, Ajayi VO, Adefolalu DO (2015) Mean state and kinematic properties of mesoscale convective systems over West Africa. Theor Appl Climatol. https://doi.org/10.1007/s0070 4-015-1412-3

38. Road J, Chen SC, Kanamistu M (2003) US regional climate simulation and seasonal forecasts. J Geophys 108:8606. https://doi. org/10.1029/2002JD002232

39. Santese M, Perrone MR, Zaker AS, De Tomasi F, Giorgi F (2010) Modeling of Saharan dust outbreaks over the Mediterranean by RegCM3: case studies. Atmos Chem Phys 10:133-156. https:// doi.org/10.5194/acp-10-133-2010

40. Sato T, Miura H, Satoh M, Takayabu YN, Wang Y (2009) Diurnal cycle of precipitation in the tropics simulated in a global cloudresolving model. J Clim 22:4809-4826

41. Sayer AM, Thomas GE, Palmer PI, Grainger RG (2010) Some implications of sampling choices on comparisons between 
satellite and model aerosol optical depth fields. Atmos Chem Phys 10:10705-107016. https://doi.org/10.5194/acp-10-10705 $-2010$

42. Schiermeir $Q$ (2011) Increased flood risk linked to global warming. Nature 471:316. https://doi.org/10.1038/470316a

43. Sen Roy S, Balling RC (2007) Diurnal variations in summer season precipitation in India. Int J Climatol 27:969-976

44. Sheffield J, Wood EF (2008) Projected changes in drought occurence under future global warming from multi-model, multi-scenario, IPCC AR4 simulations. Clim Dyn 12(1):79-105. https://doi.org/10.1007/s00382-007-0340-z

45. Slingo A, Hodges Kl, Robinson GJ (2004) Simulation of the diurnal cycle in a climate model and its evaluation using data from Meteosat 7. Q J R Meteorol Soc 130:1449-1467

46. Solmon F, Elguindi N, Mallet M (2012) Radiative and climate effects of dust over West Africa, as simulated by a regional climate model. Clim Res 52:97-113

47. Solmon F, Giorgi F, Liousse C (2006) Aerosol modelling for regional climate studies: application to anthropogenic particles and evaluation over a European/African domain. Tellus $B$ 58:51-72

48. Vondou DA, Yepdo DZ, Djiotang Tchotchou LA (2018) Diurnal cycle of convective cloud occurrences over Cameroon during June-August. J Indian Soc Remote 46(5):829-845. https://doi. org/10.1007/s12524-017-0747-x

49. Wang GL, Eltahir EAB (2002) Impact of CO2 concentration changes on the biosphere-atmosphere system of West Africa. Glob Change Biol 8:1169-1182. https://doi.org/10.104 6/j.1365-2486.2002.00542.x

50. Wang $Y$, Zhou L (2005) Observed trends in extreme precipitation events in China during 1961-2001 and the associated changes in large-scale circulation. Geophys Res Lett. 32:L9707. https:// doi.org/10.1029/2005GL022574

51. Wilks DS (2006) Statistical methods in the atmospheric science. Academic Press, Burlington

52. Zhao C, Liu X, Ruby Leung L, Hagos S (2011) Radiative impact of mineral dust on monsoon precipitation variability over West Africa. Atmos Chem Phys 11:1879-1893 